\title{
The Effect of Kinesio Taping on Pain, Muscle Strength and Balance Control Ability by Age Group: A Literature Review
}

\author{
So-Jeong Lee, Dongyeop Lee, Ji-Heon Hong, Jae-Ho Yu, Jin-Seop Kim, Seong-gil Kim \\ Department of Physical Therapy, College of Health Science, Sunmoon University, Asan, Republic of Korea
}

Purpose: The purpose of this study is to objectively and systematically investigate the effect of Kinesio taping by organizing and analyzing the research results using effect size.

Methods: A total of 1,000 papers was searched, and 100 of them were selected the first time. Afterward, the effects of taping were analyzed and classified papers that studied balance, muscle strength, and pain, and finally 34 papers were selected. The effect size was calculated using the Effect Size Calculators (University of Colorado, USA) program. Statistical analysis was performed by using PASW Statistics software version 23.0 (IBM Co., Armonk, NY, USA). Descriptive statistics were used to obtain the effect size and confidence interval for each group.

Results: In a study related to balance control ability, the effect size was 1.519 in the young subjects group (20-39 years old), and the effect size in the elderly group (65 years or older) was 0.360 . In a study related to muscle strength, the effect size was 0.469 in the group of young subjects and 0.250 in the middle-aged group (40-65 years old), and the effect size of the elderly group was 0.848 . In the study related to pain control, the effect size was 0.469 in the young group, the effect size of the middle-aged group was 0.972 , and the effect size of the elderly group was 1.040 .

Conclusion: Kinesio taping differed in the degree of effect according to the age group of the subjects, but it was effective in balance control ability, muscle strength, and pain.

Keywords: Balance, Kinesio taping, Muscle strength, Pain control

\section{INTRODUCTION}

Recently, taping therapy among various intervention methods in the field of physical therapy has attracted attention. ${ }^{1,2}$ Taping therapy is the wrapping of tape around a joint, muscle, or ligament to prevent or treat an injury. Such taping therapy helps physical activity by relieving pain and balancing the body. ${ }^{3-5}$ Kinesio taping is effective in suppressing or promoting muscle tension by attaching it to the skin of the relevant muscle to normalize the action of the main muscle that moves the joint. ${ }^{5-7}$ Also, Kinesio taping is known as a safe treatment method due to its continuing effect and simple usage. . $^{2,5-7}$

To summarize the mechanisms of Kinesio taping claimed in previous studies, taping assists joints, reducing the load on muscles or tendons, and pulling the skin to reduce pressure on blood vessels so that circulation is improved. And there was pain relief by the gate control theory. ${ }^{8}$
Jeon ${ }^{9}$ reported that the application of taping affects muscle balance, and Yam et al. ${ }^{10}$ reported that the improvement of the muscle coordination function of taping has a positive effect in terms of muscle efficiency.

And in the thesis of Jeon ${ }^{9}$, there was a significant difference in the amount of change in the total balance score after applying Kinesio taping. In addition, Lee ${ }^{11}$ stated that after taping was applied, there was a significant difference in both static and dynamic balance compared to before the experiment.

Another previous study, Lee et al. ${ }^{12}$ stated that there was a significant effect size in the ankle application and neck application.

In previous studies related to muscle strength, there have been many studies showing that when Kinesio taping is applied, muscle strength increases. ${ }^{13}$ When the taping was applied, it was said that there was an effect of increasing muscle strength in various subjects such as young adults, middle-aged and elderly people. ${ }^{13-15}$ 
Taping is also frequently used in various diseases and subjects for pain control. It is mainly used for muscle damage, but it is applied to various subjects other than muscle damage. ${ }^{16-18}$

As above, the analysis of the results of the papers that studied the effects of taping according to balance control, muscle strength, and pain control showed that balance control, muscle strength, and pain control are all effective. However, there are still few studies on objective numerical analysis to determine how effective it is.

In addition, many studies on the difference in age-specific effects have not been conducted yet. An objective numerical analysis showing the agespecific effects of Kinesio taping and the extent of the effects is a key and essential part of evidence-based treatment. To this end, it is necessary to review and objective analysis of studies on the intervention of Kinesio taping.

Therefore, the purpose of this study is to objectively and systematically investigate the effect of Kinesio taping by organizing and analyzing the research results using effect size.

\section{METHODS}

\section{Data collection}

1) Data search database

This study searched journals registered by the Korea Research Foundation among the journals in the field of physical therapy in the academic subject classification. As a database for literature search, RISS (Research information sharing service), National Assembly Library, and Medical Research Information Center were used. The original texts of published papers were collected on the website of each journal.

\section{2) Selected search word}

Korean and English were used as search words, and the words 'kinesio taping', 'taping', and 'balance, muscle strength, pain' were used as the main search words.

\section{Classification method}

\section{1) Selection criteria}

In this study, studies that satisfy the following conditions were selected.

(1) Randomized controlled trial and non-randomized controlled trial

(2) Papers using Kinesio taping

(3) Research with objective results and numerical values

(4) Research related to muscle strength, balance control ability, and pain control
(5) A study measuring the research results (muscle strength, balance control ability, pain control) related to at least one dependent variable

\section{2) Exclusion criteria}

Studies that have been duplicated, studies in which the original text cannot be verified, and studies in which appropriate research results are not provided were excluded.

\section{3) Research selection process}

Researches were searched for each database using the search word and search strategy set in this study, and 1,000 papers published from 2005 to 2020 were searched. Among them, 100 papers that meet the purpose of this study were selected for the first time. Afterward, the effects of taping were analyzed and classified papers that studied balance, muscle strength, and pain, and finally 33 papers were selected (Figure 1).

\section{Analysis method}

\section{1) Quantitative analysis of research results}

The studies used in this study were studies in which taping was applied to the experimental group to compare the effect with the control group, and the effect size of each study was derived as Cohen's D as a quantitative result. ${ }^{18}$

The effect of taping was analyzed by classifying the subjects into 3 groups [young subjects (20-39 years old), middle-aged (40-60 years old), and elderly (65 years old or older)] by age group of the subjects of each study.

The effect size was calculated using the Effect Size Calculators (University of Colorado, USA) program.

\section{2) Statistical analysis}

Statistical analysis was performed by using PASW Statistics software version 23.0 (IBM Co., Armonk, NY, USA). Descriptive statistics were used to obtain the effect size and confidence interval for each group.

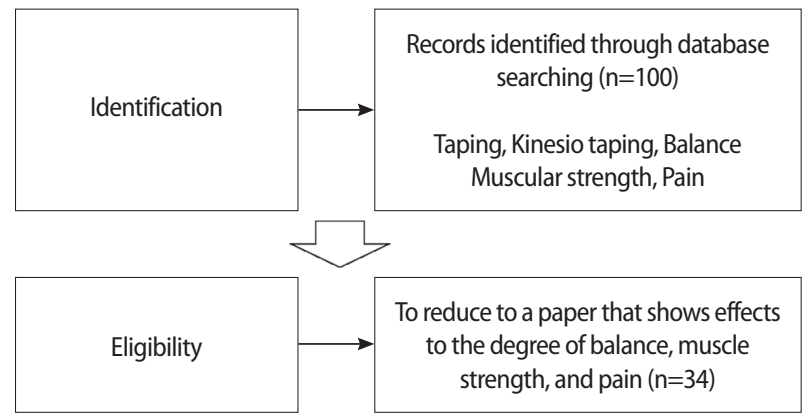

Figure 1. Summary of the Study Selection Process. 
For each dependent variable, the mean effect size (d) and 95\% confidence interval (95\% confidence interval, 95\% CI) were presented. The effect size was interpreted as follows. First, a 95\% confidence interval of the average effect size was presented, and significance was confirmed through whether 0 was included or not. Second, in the standardized mean difference, according to the effect size analysis criteria, if the effect size is less than or equal to 0.2 , it is interpreted as a small effect size, if it is 0.5 , it is interpreted as a medium effect size, and if it is greater than or equal to 0.8 , it is interpreted as a large effect size.

\section{RESULTS}

\section{General characteristics of the selected study}

All of the studies included in this study were Kinesio taping intervention studies, and a total of 34 studies included in the literature review were analyzed. The publication year was 24 (70.59\%) from 2005 to 2016 and 10 (29.41\%) from 2017 to 2020 . Of these, 9 studies (26.47\%) were a dissertation for a diploma (Table 1).

There was a total of 10 studies related to the ability to control balance. Among them, 8 studies were in the younger group (20-39 years old) and 2 studies in the elderly group (65 years or older). There are many studies of young subjects and the elderly, and there are no middle-aged people (4060 years old).

Studies related to muscle strength were 10 studies in the younger group (20-39 years old), 1 study in the middle-aged (40-60 years old), and 1 study in the elderly ( 65 years and older).

There were 3 studies related to pain control in the younger group (20-39 years old), 6 studies in the middle-aged (40-60 years old), and 3 studies in the elderly ( 65 years or older). The most frequent studies were in middleaged people (40-60 years old)(Table 2).

\section{Effect of Kinesio taping on balance control ability}

There was a total of 10 studies related to the ability to control balance. In eight studies of the young subject group (20-39 years old), the effect size was 1.519 , which had a large effect size. In the elderly group (65 years or older) studies, the effect size was 0.360 , which had a small effect size. In both age group studies, the $95 \%$ confidence interval did not contain 0 , indicating that it had a significant effect (Table 3).

\section{Effect of Kinesio taping on muscle strength}

There was a total of 11 studies related to muscle strength. In 10 studies of young subjects (ages 20-39), the effect size was 0.469, which had a moderate effect size. In the middle-aged group study (40-65 years old), the effect size was 0.250 , which had a small effect size. In the elderly group study (65 years or older), the effect size was 0.848 , which had a large effect size.

In all age group studies, the $95 \%$ confidence interval did not contain 0 , indicating that it had a significant effect (Table 4).

\section{Effect of Kinesio Taping on Pain Control}

There was a total of 12 studies related to pain control. In the study of young subjects (ages 20-39), there was an effect size of 0.468 moderate. In the middle-aged study (40-65 years old), the effect size was 0.972, which had a large effect size. In the elderly group study (65 years or older), the effect size was 1.040, which had a large effect size. In all age group studies, the $95 \%$ confidence interval did not contain 0 , indicating that it had a significant effect (Table 5).

\section{DISCUSSION}

All the studies included in this study were Kinesio taping intervention studies, and a total of 33 studies included in the literature review were analyzed. When Kinesio taping was applied, we searched the papers to find out how much the difference between balance control, muscle strength, and pain before and after was effective. To search for papers related to Kinesio taping, I searched Kinesio Taping at the sites of Reese, the National Assembly Library, and the Medical Research Information Center. Then, 100 papers were found and subdivided into papers comparing balance, muscle strength, and pain. The effect size was then analyzed using Cohen's D.

There was a total of 10 studies related to the ability to control balance. In eight studies of young subjects (ages 20-39), the effect size was 1.519, which had a large effect size. In the elderly group study (65 years or older), the effect size was 0.360 , which had a small effect size.

In previous studies, Jeon ${ }^{8}$ reported that the application of taping affects muscle balance, and Yam et al. ${ }^{9}$ reported that the improvement of muscle coordination function by taping has a positive effect on the aspect of muscle efficiency. In addition, in the paper of Choi and Lee ${ }^{19}$, it was found that there was a significant difference in the amount of change in the total balance score after application of Kinesio taping than before application of Kinesio taping.

In addition, Lee ${ }^{10}$ reported that there was a significant difference between the static balance and the dynamic balance after the taping was applied when compared to before the experiment. And Lee ${ }^{20}$ reported that 
Table 1. General subject characteristics

\begin{tabular}{|c|c|c|c|c|c|c|}
\hline \multirow{2}{*}{ Author (yr) } & \multicolumn{2}{|c|}{ Participants } & \multirow{2}{*}{$\begin{array}{c}\text { Intervention } \\
\text { Place }\end{array}$} & \multirow{2}{*}{ Comparison } & \multicolumn{2}{|l|}{ Outcome } \\
\hline & Experiment & Other group & & & Measuring method & Outcom variables \\
\hline \multirow[t]{2}{*}{ Jun (2015) } & $N=17$ & None & Ankle Jt & None & Balance system & Balance ability \\
\hline & & & & & GAITRite system & Walking ability \\
\hline Lee (2009) & $N=10$ & $N=10$ & Ankle Jt, Neck & Spiral taping & Biodex Balance System & Balance ability \\
\hline \multirow[t]{2}{*}{ Park (2005) } & $N=14$ & None & $\begin{array}{l}\text { Rectus femoris muscle, } \\
\text { biceps femoris muscle, } \\
\text { Tibialis anterior muscle, } \\
\text { gastrocnemius muscle, } \\
\text { sartorius muscle }\end{array}$ & None & $\begin{array}{c}\text { EMG (ME100B,Biopac System) } \\
\text { Cybex test }\end{array}$ & $\begin{array}{l}\text { Muscle strength, } \\
\text { muscle activation }\end{array}$ \\
\hline & & & Ankle Jt, Neck & & & \\
\hline Lee et al. (2010) & $N=20$ & None & & None & Biodex Balance System & Balance ability \\
\hline Lee et al. (2008) & $N=23$ & None & $\begin{array}{l}\text { Pain location (back, } \\
\text { knee, ankle, arm, } \\
\text { wrist, shoulder) }\end{array}$ & None & Visual Analog Scale (VAS) & Pain \\
\hline Lee (2008) & $N=15$ & None & Ankle Jt & None & Biodex pro system3 & Muscle strength \\
\hline Lee (2017) & $N=31$ & $N=32$ & Knee Jt & None & Visual Analog Scale (VAS) & Pain \\
\hline Kwon et al. (2020) & $N=15$ & $N=15$ & Ankle Jt & Dynamic taping & $\begin{array}{l}\text { Wii Balance Board, Functional reach } \\
\text { test, Star excursion balance test }\end{array}$ & Balance ability \\
\hline Joo et al. (2019) & $N=15$ & $N=15$ & Ankle Jt & Ankle muscle & Timed up and go test & Balance ability \\
\hline Park (2005) & $N=15$ & None & Knee Jt & None & Biodex system III & Muscle strength \\
\hline Kim et al. (2009) & $N=10$ & $N=10 \quad N=10$ & Ankle Jt & Strength exercise & Dynamic Balance System & Balance ability \\
\hline \multirow[t]{2}{*}{ Oh \& Lee (2019) } & $N=20$ & None & Ankle Jt & None & Visual Analog Scale (VAS) & Pain \\
\hline & & & & & Myosystem TM DTS & Muscle activation \\
\hline Park et al. (2010) & $N=15$ & $N=15 \quad N=15$ & $\begin{array}{l}\text { Erector spine muscle, } \\
\text { lumbar Jt }\end{array}$ & None & Visual Analog Scale (VAS) & Pain \\
\hline \multirow[t]{2}{*}{ Kim (2015) } & $N=32$ & None & $\begin{array}{l}\text { Six taping methods re- } \\
\text { lated with trapezius }\end{array}$ & None & Algometer, Visual Analog Scale (VAS) & Pain \\
\hline & & & Gastrocnemius muscle & & & \\
\hline Kang (2011) & $N=20$ & None & & $\begin{array}{l}\text { Compression } \\
\text { stocking }\end{array}$ & Visual Analog Scale (VAS) & Pain \\
\hline Kim (2017) & $N=15$ & None & Trunk muscles & None & TKK-5402 & Muscle strength \\
\hline Seo et al. (2012) & $N=10$ & $N=10$ & Medial epicondyle & None & Visual Analog Scale (VAS) & Pain \\
\hline Cho et al. (2012) & $N=10$ & $N=10 \quad N=10$ & Ankle Jt & Non-elastic Taping & MatScan & Balance ability \\
\hline Lee (2016) & $N=25$ & None & Trunk muscle & None & Wii Balance Board & Balance ability \\
\hline Yu \& Lee (2018) & $N=13$ & $N=13 \quad N=13$ & Ankle Jt & $\begin{array}{l}\text { Static stretching, } \\
\text { Ultrasound }\end{array}$ & Space Balance 3D & Balance ability \\
\hline Kim (2013) & $N=7$ & None & Ankle Jt & None & CSMI medical solution & Muscle strength \\
\hline Yeo et al. (2008) & $N=33$ & None & Wrist Jt & Wrist supporter & dynamometer & Muscle strength \\
\hline Yang \& Lee (2006) & $N=25$ & None & Shoulder Jt & None & Visual Analog Scale (VAS) & Pain \\
\hline Suk et al. (2013) & $N=10$ & $N=10 \quad N=9$ & $\begin{array}{l}\text { Trunk muscles, } \\
\text { Hamstring muscle }\end{array}$ & Pilates & TAKEI PHYSICAL FITNESS TEST & Muscle strength \\
\hline Lee et al. (2006) & $N=20$ & None & Elbow Jt & $\begin{array}{l}\text { Elbow band, } \\
\text { Sports taping, } \\
\text { McConnel taping }\end{array}$ & Hand Dynamometer & Muscle strength \\
\hline Lee et al. (2010) & $N=16$ & $N=12$ & Wrist Jt & None & $\begin{array}{c}\text { Baseline Pneumatic Squeeze } \\
\text { Dynamometer }\end{array}$ & Muscle strength \\
\hline Lee \& Jung (2005) & $N=10$ & $N=10$ & Trunk spinous process & None & Pressure Algometer & Pain \\
\hline Kim \& Yoon (2019) & $N=15$ & $N=17 \quad N=15$ & Shoulder Jt & Himo training, & Visual Analog Scale (VAS) & Pain \\
\hline Lee (2005) & $N=7$ & $N=7 \quad N=7$ & Knee Jt & $\begin{array}{l}\text { Training group/ } \\
\text { control croup }\end{array}$ & Biodex system3 (dynamometer) & Muscle strength \\
\hline Jung (2011) & $N=10$ & $N=10 \quad N=10$ & Shoulder Jt & None & Visual Analog Scale (VAS) & Pain \\
\hline Lee \& Kwon (2011) & $N=40$ & None & Erector spine muscle & None & Back-D (Japan) & Muscle strength \\
\hline Jeon (2015) & $N=20$ & None & Shoulder Jt, Knee Jt & None & Cybex & Muscle strength \\
\hline Lee et al. (2000) & $N=20$ & $N=20$ & Shoulder Jt & None & Visual Analog Scale (VAS) & Pain \\
\hline Choi (2018) & $N=12$ & $N=12$ & $\begin{array}{l}\text { Quadriceps femoris } \\
\text { muscle }\end{array}$ & None & O’Connor formula (1RM) & Muscle strength \\
\hline
\end{tabular}


Table 2. Classification by variable and age

\begin{tabular}{lccc}
\hline Variable & Age & Percent & N \\
\hline Balance control ability & $20-39$ & 80 & 8 \\
& $40-65$ & 0 & 0 \\
& Over 65 & 20 & 2 \\
Total & & 100 & 10 \\
Strength & $20-39$ & 90.9 & 10 \\
& $40-65$ & 8.3 & 1 \\
& Over 65 & 8.3 & 1 \\
Total & & 100 & 12 \\
Pain control & $20-39$ & 25 & 3 \\
& $40-65$ & 50 & 6 \\
Total & Over 65 & 25 & 3 \\
\hline
\end{tabular}

Table 3. Analysis of effect size on the balance control ability of Kinesio taping

\begin{tabular}{|c|c|c|c|c|}
\hline \multirow{2}{*}{ Variable } & \multirow{2}{*}{ Age } & \multirow{2}{*}{$\begin{array}{c}\text { ES } \\
\text { Cohen's d }\end{array}$} & \multicolumn{2}{|c|}{$95 \% \mathrm{Cl}$} \\
\hline & & & Lower & Upper \\
\hline Balance control & $20-39$ & 1.519 & 0.290 & 2.956 \\
\hline \multirow[t]{2}{*}{ ability } & $40-65$ & - & - & - \\
\hline & Over 65 & 0.360 & 0.226 & 0.494 \\
\hline
\end{tabular}

ES: effect size, Cl: confidence interval.

the effect was proved by showing the results of a study showing the significance of balance and gait.

Another previous study, Lee et al. ${ }^{11}$ reported that there was an effect size in the ankle application and neck application. From the results of these previous studies and comprehensive analysis, it was found that Kinesio taping has an effect on balance.

There was a total of 12 studies related to muscle strength. In 10 studies of young subjects (ages 20-39), the effect size was 0.469, which had a moderate effect size. In the middle-aged group study (40-65 years old), the effect size was 0.250 , which had a small effect size. In the elderly group study ( 65 years or older), the effect size was 0.848 , which had a large effect size.

As for previous studies that investigated the effect of taping on muscle strength, Lee ${ }^{21}$ reported that the group who took taping treatment during lower extremity exercise showed a significant difference in the comparison of muscle strength reduction after exercise than the group without taping.

In another previous study, Suk et al. ${ }^{22}$ reported that there was a slight increase in lumbar muscle strength. And in the study of de Jesus et al. ${ }^{23}$, there was a significant difference when comparing muscle strength according to the treatment period. In addition, Park et al. ${ }^{24}$ reported that there were significant differences in muscle strength between groups,
Table 4. Analysis of effect size on the strength of Kinesio taping

\begin{tabular}{|c|c|c|c|c|}
\hline \multirow{2}{*}{ Variable } & \multirow{2}{*}{ Age } & ES & \multicolumn{2}{|c|}{$95 \% \mathrm{Cl}$} \\
\hline & & Cohen's d & Lower & Upper \\
\hline \multirow[t]{3}{*}{ Strength } & $20-39$ & 0.469 & 0.292 & 0.645 \\
\hline & $40-65$ & 0.250 & - & - \\
\hline & Over 60 & 0.848 & - & - \\
\hline
\end{tabular}

ES: effect size, Cl: confidence interval.

Table 5. Analysis of effect size on the pain control of Kinesio taping

\begin{tabular}{lcccccc}
\hline \multirow{2}{*}{ Variable } & \multirow{2}{*}{ Age } & ES & & \multicolumn{2}{c}{$95 \% \mathrm{Cl}$} \\
\cline { 3 - 3 } \cline { 5 - 6 } & & Cohen's d & & Lower & Upper \\
\hline Pain control & $20-39$ & 0.468 & & 0.096 & 0.840 \\
& $40-65$ & 0.972 & & 0.388 & 1.550 \\
& Over 65 & 1.040 & & 0.212 & 1.872 \\
\hline
\end{tabular}

ES: effect size, Cl: confidence interval.

measurement period, and group X measurement period. A comprehensive analysis of the results of previous studies revealed that taping has a positive effect on muscle strength.

There was a total of 12 studies related to pain control. In the study of young subjects (ages 20-39), there was an effect size of 0.468 moderate. In the middle-aged study (40-65 years old), the effect size was 0.972, which had a large effect size. In the elderly group study (65 years or older), the effect size was 1.040, which had a large effect size.

A study by Kang ${ }^{25}$ confirmed that the application of taping therapy can reduce joint pain. In addition, the study results of Lee et al. ${ }^{26}$ said that there was a significant difference and that the hypothesis that the experimental group to which taping therapy was applied would decrease knee pain was supported. In the study results of Han et al. ${ }^{27}$, it was confirmed that pain decreased after 1 or 2 weeks of treatment compared to before treatment. Kiml reported that taping showed a significant difference in pain reduction after treatment. In this way, when the results of previous papers and the results of this study were comprehensively analyzed, it was possible to prove that Kinesio taping is effective in pain control.

In addition, by comprehensively analyzing the contents of previous papers, the mechanisms for the positive effect of Kinesio taping can be summarized into three. First, taping has a mechanical effect, such as reducing the load on a muscle or tendon by assisting the joint; second, by pulling on the skin to reduce the pressure on the blood vessels so that circulation is improved; third, pain relief by the gate control theory. ${ }^{8}$

In conclusion, Kinesio taping was effective in controlling balance, muscle strength, and pain. The effect of Kinesio taping on balance control was most effective in young adults, and it was also effective in helping the el- 
derly in balance control to some extent. Muscle strength was mainly effective for young adults, and the effect on pain control was effective for subjects of all ages, especially for middle-aged and elderly people.

The limitation of this study is that the number of analyzed papers is limited, and 100 papers were searched and classified, but due to various variables, the effect size was verified with only 34 papers. In addition, most of the previous studies applying taping were made for the general public and sports players, so the subjects could not represent the patients. Another limitation of this study is that the age group of the study subjects was biased because the previous studies that applied taping often conducted research with young subjects.

However, the effect of Kinesio taping was evident, and it was found that the size of the effect classified in each subdivision showed a difference according to the age group. In future studies, studies on various variables other than muscle strength, balance control ability, and pain control by applying Kinesio taping should be analyzed.

\section{REFERENCES}

1. Kim J. An influence of taping treatment on shoulder pain and physiological change. J Korean Soc Integr Med. 2015;3(3):25-33.

2. Park SJ. Effect of inspiratory muscle training with elastic taping on forced vital capacity and sway area in stroke patients. J Kor Phys Ther. 2020; 32(2):121-5.

3. Kim BG, Cho WS, Kim YS. Effects of kinesio taping on balance and gait in patients with stroke: a systematic review and meta-analysis of studies in korea. J Kor Phys Ther. 2021;33(1):21-7.

4. Um YJ, Jang HY, Lee SM. Taping therapy simultaneously applied to the ankle and hip joint: effect on balance and gait in patients with chronic stroke. J Kor Phys Ther. 2019;31(1):49-55.

5. Kim BR, Kang TW. A systematic review of elastic taping effect of patients with stroke. J Kor Phys Ther. 2018;30(4):101-7.

6. Park JC, Park MS, Hwang TY. The effect of kinesio taping pre-intervention on delayed onset muscle soreness. J Kor Phys Ther. 2019;31(1):1823.

7. Jung D. Effect of weight-bearing pattern and calcaneal taping on heel width and plantar pressure in standing. J Kor Phys Ther. 2020;32(1):2933.

8. Artioli DP, Bertolini GRF. Kinesio taping: application and results on pain: systematic review. Braz J Phys Ther. 2014;21(1):94-9.

9. Jun YT. The effect of pes planus on balance and gait in kinesio taping. Gachon University. Dissertation of Master's Degree. 2015.

10. Yam TT, Or PP, Ma AW et al. Effect of kinesio taping on $y$-balance test performance and the associated leg muscle activation patterns in children with developmental coordination disorder: a randomized controlled trial. Gait Posture. 2019;68:388-96.

11. Lee BH. Changes in balance according to the region where therapeutic taping is applied. Dongshin University. Dissertation of Master's Degree. 2009.

12. Lee BH, Kim CK, Lee HS et al. The effects of kinesio taping applied to regions on balance index. Journal of Coaching Development. 2010;12 (4):99-104.

13. Csapo R, Alegre LM. Effects of kinesio taping on skeletal muscle strength-a meta-analysis of current evidence. J Sci Med Sport. 2015; 18(4):450-6.

14. Cebolla EC, Rodacki AL, Bento PC. Balance, gait, functionality and strength: comparison between elderly fallers and non-fallers. Braz J Phys Ther. 2015;19(2):146-51.

15. Mansouri Jamshidi K, Jalali S, Roghani T et al. Gastrocnemius kinesiotaping to improve dynamic balance performance in middle-age healthy men: protocol of randomized controlled trial. Muscles Ligaments Tendons J. 2020;10(3):430-5.

16. Wu WT, Hong CZ, Chou LW. The kinesio taping method for myofascial pain control. Evid Based Complement Alternat Med. 2015;2015: 950519.

17. Mostafavifar M, Wertz J, Borchers J. A systematic review of the effectiveness of kinesio taping for musculoskeletal injury. Physician Sportsmed. 2012;40(4):33-40.

18. Mikami DLY, Furia CLB, Welker AF. Addition of kinesio taping of the orbicularis oris muscles to speech therapy rapidly improves drooling in children with neurological disorders. Dev Neurorehabil. 2019;22(1):13-8.

19. Cohen J. Statistical power analysis for the behavioral sciences. Massachusetts, Academic press, 2013:19-20.

20. Choi HS, Lee JH. Immediate effect of balance taping using kinesiology tape on dynamic and static balance after ankle muscle fatigue. Healthcare. 2020;8(2):162.

21. Lee YJ. The effects of low trunk kinesio taping on balance ability and gait function in chronic stroke patients. Kyungnam University. Dissertation of Master's Degree. 2016.

22. Lee JM. The effects of knee taping on muscle function and fatigue recovery for training during 8 weeks isotonic. Gachon University. Dissertation of Master's Degree. 2005.

23. Bokyung S, Jaewook O, Sojeong $\mathrm{L}$ et al. The effect of pilates and taping on flexibility and muscle strength of low back. J Korean Soc Integr Med. 2013;1(1):23-31.

24. de Jesus JF, de Almeida Novello A, Nakaoka GB et al. Kinesio taping effect on quadriceps strength and lower limb function of healthy individuals: a blinded, controlled, randomized, clinical trial. Phys Ther Sport. 2016;18:27-31.

25. Park MC, Kim EY, Ha MS. Effects of taping therapy by methods on back pain and muscle flexibility of bus drivers's. J Korea Acad Industr Coop Soc. 2010;11(11):4367-73.

26. Kang SA. Effects of taping therapy on edema, pain and fatigue of lower extremities in hospital nurses. Konkuk University. Dissertation of Master's Degree. 2011.

27. Lee JH. Effects of taping therapy on knee pain and depression in older adult women. J Korea Acad Industr Coop Soc. 2017;18(2):619-24.

28. Yang KH, Lee YM. An influence taping therapy toward upper limb end part having on shoulder pain. JKPTS. 2006;13(2):47-55. 